\title{
A film model for free convection over a vertical porous plate with blowing or suction
}

\author{
H. J. H. Brouwers, Enschede, The Netherlands
}

\begin{abstract}
A film model is described for free convective heat transfer and friction in the presence of wall suction or injection. The analysis yields a thermal correction factor, which appears to be the classical (Ackermann) expression, and a novel friction correction factor, derived here for the first time. Both correction factors are applied to free convection along a vertical flat porous plate for values of the Prandtl number of $0.73,1$ and 7 . Subsequently, the film theory predictions are compared with the numerical and asymptotic results of a boundary layer analysis, performed by previous investigators. On the basis of this comparison, a modified correction factor is proposed which correlates excellently with the results of the boundary layer analyses.
\end{abstract}

Ein Filmmodell für freie Konvektion

an einer senkrechten porösen Platte mit Ausblasung und Absaugung

Zusammenfassung. Es wird ein Filmmodell beschrieben, das für freie Konvektion den Wärmeübergang und den Reibungsbeiwert bei Wandaus- oder -einblasung $\mathrm{zu}$ bestimmen gestattet. Die Untersuchung liefert einen thermischen Korrekturfaktor, der mit der klassischen Ackermann-Korrektur übereinstimmt und einen neuen, hier erstmalig abgeleiteten Korrekturfaktor für den Reibungsbeiwert. Beide Korrekturfaktoren werden zur Ermittlung der freien Konvektionsströmung entlang einer senkrechten, ebenen, porösen Platte herangezogen (für Prandtl-Zahlen: 0,73-1-7). Anschließend erfolgt ein Vergleich der Voraussagen nach der Filmtheorie mit den numerisch aus einer asymptotischen Grenzschichtanalyse erhaltenen Ergebnissen früherer Autoren. Aus diesem Vergleich resultiert ein modifizierter Korrekturfaktor für den Reibungsbeiwert, der eine ausgezeichnete Korrelation mit den Ergebnissen nach der Grenzschichttheorie liefert.

\section{Symbols}

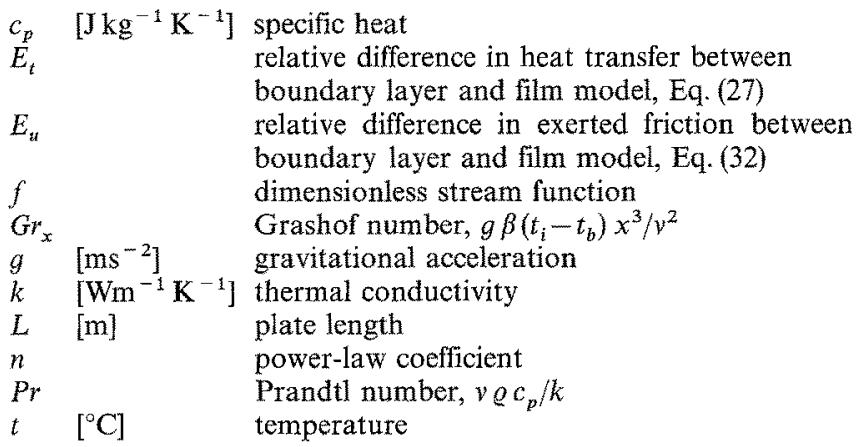

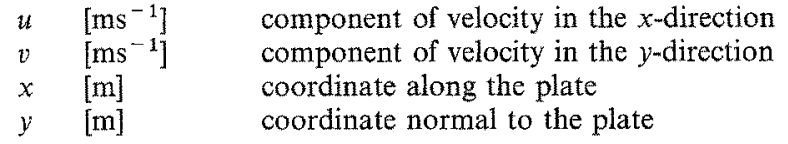

Greek symbols

\begin{tabular}{|c|c|c|}
\hline$\beta$ & {$\left[\mathrm{K}^{-1}\right]$} & volumetric coefficient of thermal expansion \\
\hline$\delta_{t}$ & [m] & film thickness \\
\hline$\eta$ & & similarity variable $\left(=y\left(G r_{x} / 4\right)^{1 / 4} / x\right)$ \\
\hline$\Theta_{i}$ & & $\begin{array}{l}\text { ratio of heat transfer with and without wall tran- } \\
\text { spiration }\end{array}$ \\
\hline$\Theta_{n}$ & & $\begin{array}{l}\text { ratio of exerted friction with and without wall } \\
\text { transpiration }\end{array}$ \\
\hline$\Theta$ & & dimensionless temperature $\left(=\left(t_{b}-t\right) /\left(t_{b}-t_{i}\right)\right)$ \\
\hline$y$ & {$\left[\mathrm{~m}^{2} \mathrm{~s}^{-1}\right]$} & kinematic viscosity \\
\hline$\Omega$ & & function for friction correction, Eq. (22) \\
\hline$\varrho$ & {$\left[\mathrm{kg} \mathrm{m}^{-3}\right]$} & density \\
\hline$\phi_{u}$ & & dimensionless frictional wall mass flux \\
\hline$\phi_{i}$ & & dimensionless thermal wall mass flux. \\
\hline$\Xi$ & & Ackermann function, Eq. (10) \\
\hline
\end{tabular}

Subscripts

asym pertaining to asymptotic approximation b bulk or ambient fluid

blm pertaining to boundary layer model

fm pertaining to film model

$i \quad$ wall

Superscripts

\begin{tabular}{ll}
$*$ & pertaining to zero suction \\
- & differentiation with respect to $\eta$ \\
+ & mean \\
\hline
\end{tabular}

\section{Introduction}

For many years the classical film model correction factors have been used successfully to predict the effects of wall mass transfer on transport phenomena, such as skin friction and heat and mass transfer. The correction factors can be derived from a stagnant film analysis and applied to systems using either an imposed (wall suction or injection) mass flux or vapour(s) mass flux (condensation or evaporation). Recent 
reviews of the film model are found in Bannwart [1], Bannwart and Bontemps [2], Brouwers and Chesters [3] and Brouwers [4]. The former two authors extended the model to include the effect of mass transfer on film thickness, the latter investigator added fog formation to the model.

The film model expressions have been applied mainly to forced convective transport phenomena. Until now, free convective friction with mass transfer has not been examined with the film model. This can probably be attributed to the fact that the classical film model correction factor for friction arises from a bulk velocity and hence is not particularly suited to free convection, where the ambient fluid is at rest. This classical correction factor was first derived by Mickley et al. [5]. It has been applied to forced convective flow through channels with porous walls by Brouwers and Chesters [3]. In the momentum equation for the film from which the forced convection friction correction factor was derived the buoancy and pressure gradient terms were omitted; though this neglect is allowable for forced convective flow, it is unacceptable for free convection.

Hence, in this note a stagnant film is considered in which buoyancy is retained in the momentum equation and an outer flow is absent. The solution of the energy equation for the film yields the temperature profile and thermal correction factor. Invoking the Oberbeck -Boussinesq approximations, the temperature profile in the film is inserted in the momentum equation. Solving this equation then yields the correction factor, derived here for the first time, for the effect of mass transfer on free convective friction. Subsequently, both the thermal and frictional correction factor are compared extensively with the theoretical results of Eichhorn [6] and Merkin [7,21]. These latter results are based on a numerical and asymptotic boundary layer analysis of laminar free convection over a permeable vertical plate with wall transpiration. The application and comparison is restricted to laminar free convection because, to the author's knowledge, the literature on turbulent free convective flow with wall suction or injection is not yet available.

\section{Film equations and derivation of correction factors}

In this section the energy and momentum equations for a film in which there is an imposed induced velocity caused by wall injection or blowing, are derived and solved analytically. The solutions are employed to define the film model correction factors.

Consider a film, as depicted in Fig. 1, through which there is a transfer of heat and momentum in the $y$-direction, with gravity parallel to the wall in the downward $x$-direction. At the permeable wall $(y=0)$ the temperature is $t_{i}$. At a distance $\delta_{t}$ the bulk temperature $t_{b}$ is attained. For the purposes of the present analysis the physical properties in the film are assumed to be constant, with the exception of the density, and the mixture is assumed to behave as an ideal and Newtonian gas.

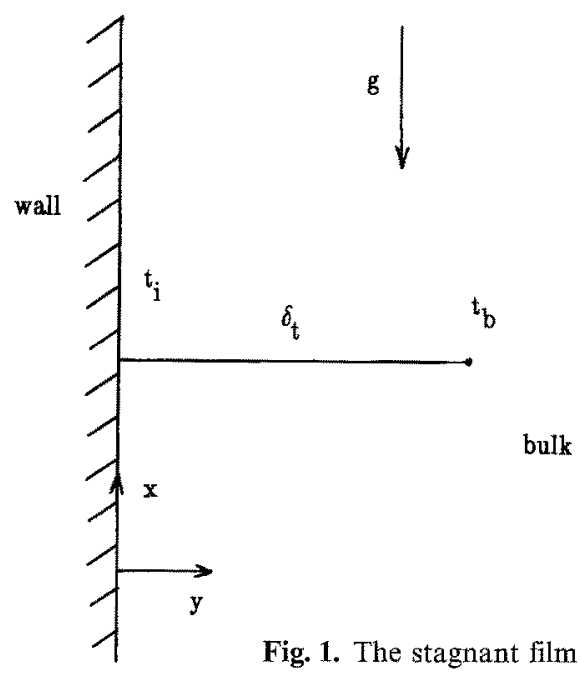

\subsection{Energy equation}

In order to investigate the effect of the induced velocity on heat transfer, attention is focused on the energy equation for the film. Considering a steady flow and neglecting variations of $t$ in the $x$-direction, neglecting viscous dissipation, heat sources or radiation, this equation reads:

$\varrho c_{p} v \frac{d t}{\mathrm{~d} y}=k \frac{d^{2} t}{\mathrm{~d} y^{2}}$,

subject to:

$t(y=0)=t_{i}$,

$t\left(y=\delta_{t}\right)=t_{b}$.

Solution of Eq. (1), and application of boundary conditions (2) and (3) now produces a temperature profile in the film:

$t(y)=\left(t_{b}-t_{i}\right)\left(\frac{e^{-\frac{y \phi_{t}}{\delta_{1}}}-1}{e^{-\phi_{t}}-1}\right)+t_{i}$,

where $\phi_{t}$ represents the dimensionless thermal mass flux:

$\phi_{t}=-\frac{\varrho v c_{p} \delta_{t}}{k}$.

For a negligible induced velocity the temperature profile in the film is given simply by:

$t(y)^{*}=\left(t_{b}-t_{i}\right) \frac{y}{\delta_{t}}+t_{i}$,

which serves as reference level for the effect of the induced velocity on heat transfer. The asterisk represents the heat transfer in the case of zero mass transfer. The heat transfer from the fluid to the wall is described by Fourier's law as:

$q=\left.k \frac{d t}{\mathrm{~d} y}\right|_{y=0}$. 


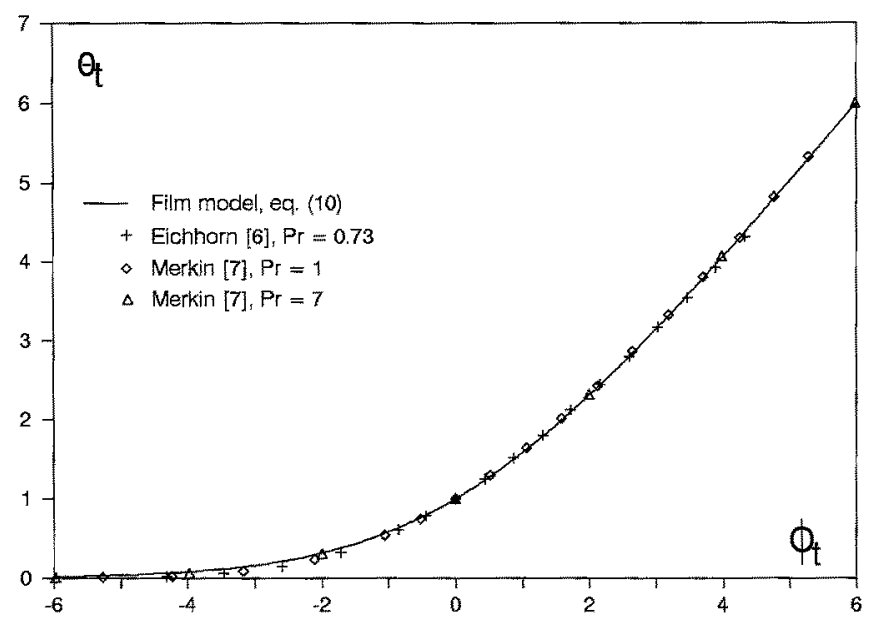

Fig. 2. The effect of transpiration on heat transfer, according to Eichhorn [6], Merkin [7] and the film model

The heat transfer from fluid to wall with an induced velocity is obtained by combining Eqs. (4) and (7):

$q=\frac{k}{\delta_{t}}\left(t_{b}-t_{i}\right)\left(\frac{-\phi_{t}}{e^{-\phi_{t}}-1}\right)$.

The heat transfer from fluid to wall without an induced velocity (i.e. $\phi_{t} \rightarrow 0$ ) is obtained by combining Eqs. (6) and (7):

$q^{*}=\frac{k}{\delta_{t}}\left(t_{b}-t_{i}\right)$

On comparing Eq. (8) with Eq. (9) the following film model correction factor is derived:

$\Theta_{t, \mathrm{fm}}=\Xi\left(\phi_{t}\right)=\frac{-\phi_{t}}{e^{-\phi_{t}}-1}$.

This thermal correction factor $\Theta_{t, \mathrm{fm}}$ is the same as for forced convective heat transfer. It is commonly referred to as Ackermann correction, as it was first derived by Ackermann [8]. In Fig. $2 \Theta_{t, \mathrm{fm}}$ is depicted as a function of $\phi_{\mathrm{t}}$.

\subsection{Momentum equation}

To examine the influence of the induced velocity on the wall shear stress, the momentum equation for the $x$-direction is investigated. Again neglecting gradients of properties in the $x$-direction this equation reads:

$v \frac{\mathrm{d} u}{\mathrm{~d} y}=y \frac{\mathrm{d}^{2} u}{\mathrm{~d} y^{2}}+\beta g\left(t-t_{b}\right)$,

with appropriate boundary conditions on $u$ at the wall and bulk:

$u(y=0)=0$

$u\left(y=\delta_{t}\right)=0$.
In Eq. (11), in contrast to the conventional film model, the body forces are retained. These forces stem from variations in density caused by the temperature gradient across the film and in which the Oberbeck-Boussinesq approximations have been invoked (note that, though these approximations are generally attributed to Boussinesq [9], they were originally set out by Oberbeck [10], see the most interesting footnote of Joseph [11]). Boundary condition (13) reflects the state of rest of the ambient fluid beyond the thermal film. Furthermore, the integral approximations of Eckert [12] and Mabuchi [13] also arose from equal thermal and momentum boundary layer thickness. Eckert [12] obtained good agreements between experiments with air $(\operatorname{Pr} \approx 0.7)$ and an approximate integral method for impermeable plates. Mabuchi [13] also obtained good agreement between the integral methode and the numerical results $(P r=0.73)$ of Eichhorn [6]. An analysis by Jaluria [14] revealed that the thermal and momentum boundary layer thicknesses are indeed of the same order of magnitude for $\operatorname{Pr} \approx 1$.

Substituting Eq. (4) into Eq. (11), integrating the resulting equation twice with respect to $y$, and applying boundary conditions (12) and (13) results in:

$$
\begin{aligned}
u(y)= & -\frac{g \beta \delta_{t}^{2}\left(t_{b}-t_{i}\right)}{v} \Theta_{t, \mathrm{fm}}\left(\frac{e^{-\frac{\phi_{t} y}{\delta_{t}}}-1}{\phi_{t} \phi_{u}^{2}(1-\operatorname{Pr}) \operatorname{Pr}}+\frac{y e^{-\phi_{t}}}{\delta_{t} \phi_{t} \phi_{u}}\right. \\
& \left.-\left(\frac{e^{-\frac{\phi_{u} y}{\delta_{t}}}-1}{e^{-\phi_{u}}-1}\right)\left(\frac{e^{-\phi_{u} P r}-1}{\phi_{t} \phi_{u}^{2}(1-\operatorname{Pr}) \operatorname{Pr}}+\frac{e^{-\phi_{t}}}{\phi_{t} \phi_{u}}\right)\right)
\end{aligned}
$$

In this equation the Prandtl number $\mathrm{Pr}$ and frictional dimensionless mass flux:

$\phi_{u}=-\frac{v \delta_{t}}{v}$,

have been introduced. It is straightforward to see that the dimensionless frictional and thermal mass fluxes are related by:

$\phi_{i}=\phi_{u} P r$.

Deriving Eq. (14) it has been assumed that $P r \neq 1$. For $\operatorname{Pr}=1$ the velocity profile follows from Eqs. (4) and (11)-(13) as:

$$
\begin{aligned}
u(y)= & -\frac{g \beta \delta_{t}^{2}\left(t_{b}-t_{i}\right)}{v} \Theta_{i, \mathrm{fm}}\left(\frac{y}{\delta_{t} \phi_{u} \phi_{t}} e^{-\frac{\phi_{u} y}{\delta_{t}}}+\frac{y}{\delta_{t} \phi_{u} \phi_{t}} e^{-\phi_{t}}\right. \\
& \left.+\left(\frac{e^{-\phi_{u}}-e^{-\frac{\phi_{u} y}{\delta_{t}}}}{e^{-\phi_{u}}-1}-1\right)\left(\frac{e^{-\phi_{u}}+e^{-\phi_{t}}}{\phi_{t} \phi_{u}}\right)\right)
\end{aligned}
$$

Without mass transfer the velocity profiles follow from Eqs. (5), (11) (with $v=0$ ), (12) and (13) as:

$u(y)^{*}=-\frac{g \beta \delta_{t}^{2}\left(t_{b}-t_{i}\right)}{v}\left(\frac{y^{3}}{6 \delta_{t}^{3}}-\frac{y^{2}}{2 \delta_{t}^{2}}+\frac{y}{3 \delta_{t}}\right)$.

The film model correction factor for skin friction is now introduced by comparing the expression for the exerted friction with an induced velocity and that without. 
The exerted shear stress by the fluid on the wall is governed by Newton's law as:

$\tau=\left.\eta \frac{\mathrm{d} u}{\mathrm{~d} y}\right|_{y=0}$.

Combining Eqs. (14) and (17) with Eq. (29) and application of Eq. (16) yields:

$$
\begin{aligned}
\tau= & -g \varrho \beta \delta_{t}\left(t_{b}-t_{i}\right) \Theta_{t, \mathrm{fm}}\left(\frac{-1}{\phi_{t} \phi_{u}(1-P r)}+\frac{e^{-\phi_{r}}}{\phi_{t} \phi_{u}}\right. \\
& \left.-\left(\frac{-1}{e^{-\phi_{u}}-1}\right)\left(\frac{e^{-\phi_{u} P_{r}}-1}{\phi_{t} \phi_{u}(1-P r) P r}+\frac{e^{-\phi_{t}}}{\phi_{t}}\right)\right), \quad(\operatorname{Pr} \neq 1) \\
\tau= & -g \varrho \beta \delta_{t}\left(t_{b}-t_{i}\right) \Theta_{t, \mathrm{fm}}\left(\frac{1}{\phi_{t} \phi_{u}}+\frac{e^{-\phi_{t}}}{\phi_{t} \phi_{u}}\right. \\
& \left.+\left(\frac{\phi_{u}}{e^{-\phi_{u}}-1}\right)\left(\frac{e^{-\phi_{u}}+e^{-\phi_{t}}}{\phi_{t} \phi_{u}}\right)\right), \quad(\operatorname{Pr}=1)
\end{aligned}
$$

The exerted friction without an induced velocity follows from Eqs. (18) and (19):

$$
\tau^{*}=-\frac{g \varrho \beta \delta_{i}\left(t_{b}-t_{i}\right)}{3} .
$$

This expression is the limiting case of Eq. (20) for $v$ (appearing in both $\phi_{u}$ and $\phi_{t}$ ) tending to zero (the limit can be determined by substituting the third-order Taylor-MacLaurin expansion around zero of the exponential functions involved into equation (20)). Comparing Eq. (20) with Eq. (21) yields as correction factor:

$$
\begin{aligned}
& \Theta_{u, \mathrm{fm}}= \Omega\left(\phi_{u}, \operatorname{Pr}\right)=-\frac{3 \Xi\left(\operatorname{Pr} \phi_{u}\right)}{\operatorname{Pr} \phi_{u}^{2}} \\
&\left(\frac{1-\frac{\Xi\left(\phi_{u}\right)}{\Xi\left(\operatorname{Pr} \phi_{u}\right)}}{1-\operatorname{Pr}}+\left(\Xi\left(\phi_{u}\right)-1\right) e^{-\operatorname{Pr} \phi_{u}}\right), \quad(\operatorname{Pr} \neq 1), \\
& \Theta_{u, \mathrm{fm}}= \Omega\left(\phi_{u}, \operatorname{Pr}\right)=-\frac{3 \Xi\left(\phi_{u}\right)}{\phi_{u}^{2}}\left(\left(2 \Xi\left(\phi_{u}\right)-1\right) e^{-\phi_{u}}-1\right), \\
& \quad(\operatorname{Pr}=1),
\end{aligned}
$$

where relations (10) and (16) have been inserted.

In Fig. $3 \Theta_{u, \mathrm{~m}}$ has been depicted as a function of $\phi_{u}$ for $\operatorname{Pr}=0.73,1$ and 7. Figure 3 illustrates that Eq. (22) predicts a friction reduction for both large suction and blowing rates. This in contrast to the correction factor for friction by forced convective flow, which predicts friction enhancement for suction and friction reduction for blowing (likewise the thermal correction), see Refs. [1-5]. Figure 3 also shows that $\Theta_{u, \mathrm{fm}}$ obtains a maximum for a negative $\phi_{u}$ when $\operatorname{Pr}=7$, that $\Theta_{u, \mathrm{fm}}$ is highest at $\phi_{u}=0$ for $\operatorname{Pr}=1$, and that the correction factor reaches a maximum for a positive $\phi_{u}$ when $P r=0.73$. Replacing $\phi_{u}$ by $-\phi_{u}$ it can be proved with equation (22) that $\Theta_{u, f m}$ is symmetrical with respect to the ordinate for $\operatorname{Pr}=1$.

In this section the temperature and velocity profiles in the film have been derived. On the basis of these solutions correction factors have been arrived at for the effect of mass

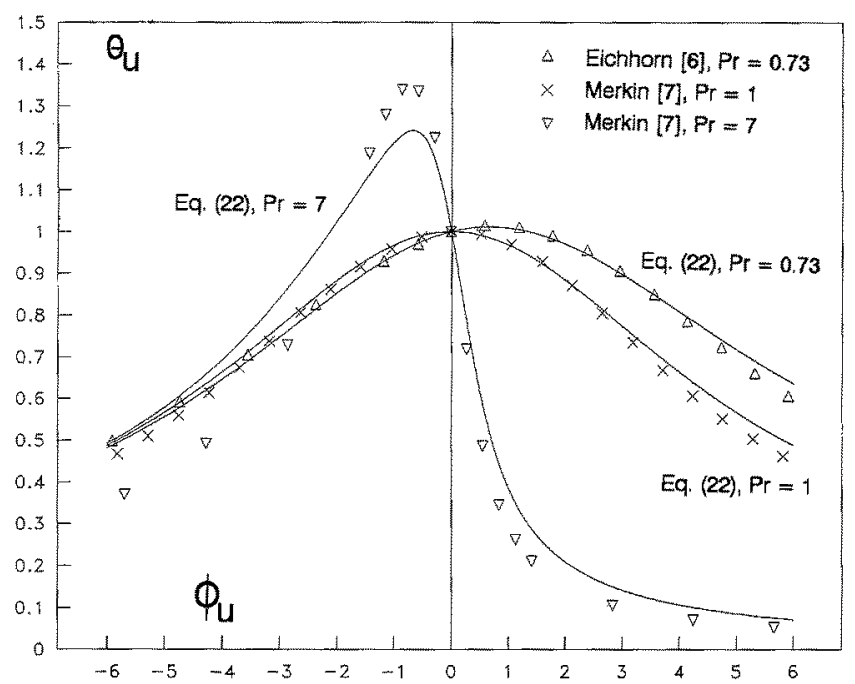

Fig. 3. The effect of transpiration on exerted friction, according to Eichhorn [6], Merkin [7] and the film model

transfer on free convective heat transfer and skin friction. In the next section these factors are applied to free convection and compared with numerical results obtained by previous investigators.

\section{Application of film model and comparison with boundary layer model}

The film model for the effect of mass transfer on both heat and momentum transfer is applied to free convective flow along an isothermal vertical plate. Subsequently the predictions of the model are compared with the results of Eichhorn [6] and Merkin [7]. These studies concern an analysis of laminar free convective boundary layer flow over a vertical plate with imposed transpiration. For the sake of completeness the studies in this field of Sparrow and Cess [15], Merkin [16], Parikh et al. [17] and Clarke [18] should also be mentioned.

Eichhorn [6] was the first to study the effect of suction and injection on free convective flow. Power law variations of wall temperature $\left(t_{i}-t_{b}=C_{1} x^{n}\right)$ and transpiration velocity $\left(v=C_{2} x^{(n-1) / 4}\right)$ were considered under which self-similar solutions of the governing equations are possible. For various wall stream function values, referred to as $f_{w}$, the dimensionless temperature gradient $-\Theta^{\prime}(0)$ and velocity gradient $f^{\prime \prime}(0)$ at the wall were determined. This numerical boundary layer analysis provided results which can be used to validate the presented free convective film model.

\subsection{Heat transfer}

As mentioned above, Eichhorn [6] obtained - $\theta^{\prime}(0)$ for various $f_{w}$. The ratio of heat transfer with and without mass 
Table 1. Values of $\Theta^{\prime}(0)^{*}$ and $f^{\prime \prime}(0)^{*}$ for various Prandtl numbers according to Ostrach [19]

\begin{tabular}{lllllll}
\hline Pr & 0.01 & 0.72 & 0.733 & 1 & 10 & 100 \\
\hline$-\Theta^{\prime}(0)^{*}$ & 0.0812 & 0.5046 & 0.5080 & 0.5671 & 1.1694 & 2.191 \\
$f^{\prime \prime}(0)^{*}$ & 0.9862 & 0.6760 & 0.6741 & 0.6421 & 0.4192 & 0.2517 \\
$-\Theta^{\prime}(0)^{*} f^{\prime \prime}(0)^{*}$ & 0.0801 & 0.3411 & 0.3424 & 0.3641 & 0.4902 & 0.5515 \\
\hline
\end{tabular}

Table 2. Numerical results of Eichhorn [6] and film model prediction of heat transfer $(n=0, P r=0.73)$

\begin{tabular}{|c|c|c|c|c|c|}
\hline $\begin{array}{l}\text { Eichho } \\
f_{w}\end{array}$ & $\begin{array}{l}{[6]} \\
-\Theta^{\prime}(0)\end{array}$ & $\begin{array}{l}\text { Eq. (23) } \\
\Theta_{t, \text { blm }}\end{array}$ & $\begin{array}{l}\text { Eq. (26) } \\
\phi_{i}\end{array}$ & $\begin{array}{l}\text { Eq. }(10) \\
\Theta_{t, \mathrm{fm}}\end{array}$ & $\begin{array}{l}\mathrm{Eq}_{. .}(27) \\
E_{t}\end{array}$ \\
\hline-1.0 & 0.00748 & 0.0148 & -4.320 & 0.0582 & $293.2 \%$ \\
\hline-0.8 & 0.0264 & 0.0521 & -3.456 & 0.113 & $116.9 \%$ \\
\hline-0.6 & 0.0725 & 0.143 & -2.592 & 0.210 & $46.9 \%$ \\
\hline-0.4 & 0.162 & 0.320 & -1.728 & 0.373 & $16.6 \%$ \\
\hline-0.2 & 0.305 & 0.602 & -0.864 & 0.629 & $4.5 \%$ \\
\hline-0.1 & 0.399 & 0.787 & -0.432 & 0.800 & $1.7 \%$ \\
\hline 0.0 & 0.507 & 1.000 & 0.000 & 1.000 & $0.0 \%$ \\
\hline 0.1 & 0.629 & 1.241 & 0.432 & 1.232 & $-0.7 \%$ \\
\hline 0.2 & 0.764 & 1.507 & 0.864 & 1.493 & $-0.9 \%$ \\
\hline 0.3 & 0.912 & 1.799 & 1.296 & 1.784 & $-0.8 \%$ \\
\hline 0.4 & 1.072 & 2.114 & 1.728 & 2.101 & $-0.6 \%$ \\
\hline 0.5 & 1.241 & 2.448 & 2.160 & 2.442 & $-0.2 \%$ \\
\hline 0.6 & 1.420 & 2.801 & 2.592 & 2.802 & $-0.04 \%$ \\
\hline 0.7 & 1.606 & 3.168 & 3.024 & 3.178 & $0.3 \%$ \\
\hline 0.8 & 1.798 & 3.546 & 3.456 & 3.569 & $0.6 \%$ \\
\hline 0.9 & 1.994 & 3.933 & 3.888 & 3.969 & $0.9 \%$ \\
\hline 1.0 & 2.192 & 4.323 & 4.320 & 4.378 & $1.2 \%$ \\
\hline
\end{tabular}

transfer readily follows as:

$\frac{\Theta^{\prime}(0)}{\Theta^{\prime}(0)^{*}}=\Theta_{t, \mathrm{blm}}$.

The film model correction factor can now be applied to free convective flow and compared with the heat transfer ratio (23) of the boundary layer model. To this end, the dimensionless mass flux $\phi_{t}$ and film thickness $\delta_{t}$ have to be assessed.

The heat flux is written in dimensionless form as:

$q^{*}=-\frac{\mathrm{k}}{x} \Theta^{\prime}(0)^{*}\left(t_{b}-t_{i}\right)\left(\frac{G r_{x}}{4}\right)^{1 / 4}$,

where $x$ is a coordinate along the wall. Ostrach [19] obtained values of $-\Theta^{\prime}(0)^{*}$, which depend on $\operatorname{Pr}$ only, for various Prandtl numbers, here listed in Table 1. Combining Eqs. (9) and (24) yields as thermal film thickness:

$\delta_{t}=-\frac{x}{\Theta^{\prime}(0)^{*}}\left(\frac{G r_{x}}{4}\right)^{-1 / 4}$.

The thermal mass flux is related to $f_{w}$ by:

$\phi_{t}=-\frac{f_{w}(n+3) P r}{\Theta^{\prime}(0)^{*}}$,

see Eqs. (5) and (25), and Eq. (11) from Ref. [6].
Table 3. Numerical results of Merkin [7] and film model prediction of heat transfer $(n=0, \operatorname{Pr}=1)$

\begin{tabular}{llllll}
\hline \multicolumn{2}{l}{ Merkin [7] } & Eq. (23) & Eq. (26) & Eq. (10) & Eq. (27) \\
$f_{w}$ & $-\Theta^{\prime}(0)$ & $\Theta_{i, \text { blm }}$ & $\phi_{t}$ & $\Theta_{t, \text { fm }}$ & $E_{t}$ \\
\hline-1.0 & 0.0021 & 0.0037 & -5.289 & 0.0268 & $624.3 \%$ \\
-0.8 & 0.0118 & 0.021 & -4.231 & 0.0624 & $197.1 \%$ \\
-0.6 & 0.0465 & 0.082 & -3.173 & 0.139 & $69.5 \%$ \\
-0.4 & 0.1341 & 0.236 & -2.116 & 0.290 & $22.9 \%$ \\
-0.2 & 0.3023 & 0.533 & -1.058 & 0.563 & $5.6 \%$ \\
-0.1 & 0.4223 & 0.745 & -0.529 & 0.759 & $1.9 \%$ \\
0.0 & 0.5672 & 1.000 & 0.000 & 1.000 & $0.0 \%$ \\
0.1 & 0.7365 & 1.298 & 0.529 & 1.288 & $-0.8 \%$ \\
0.2 & 0.9290 & 1.638 & 1.058 & 1.621 & $-1.0 \%$ \\
0.3 & 1.1430 & 2.015 & 1.587 & 1.995 & $-1.0 \%$ \\
0.4 & 1.3763 & 2.426 & 2.116 & 2.406 & $-0.8 \%$ \\
0.5 & 1.6263 & 2.867 & 2.645 & 2.847 & $-0.7 \%$ \\
0.6 & 1.8901 & 3.332 & 3.173 & 3.312 & $-0.6 \%$ \\
0.7 & 2.1646 & 3.816 & 3.702 & 3.796 & $-0.5 \%$ \\
0.8 & 2.4468 & 4.313 & 4.231 & 4.293 & $-0.5 \%$ \\
0.9 & 2.7345 & 4.821 & 4.760 & 4.801 & $-0.4 \%$ \\
1.0 & 3.0260 & 5.335 & 5.289 & 5.316 & $-0.4 \%$ \\
\hline
\end{tabular}

For $n=0$ and $\operatorname{Pr}=0.73$ values of $\Theta^{\prime}(0)$ were computed by Eichhorn [6] as a function of $f_{w}$, here summarized in Table 2 . Table 2 also includes both $\phi_{t}$, the pertaining film model correction factor $\Theta_{t, \mathrm{fm}}, \Theta_{t, \mathrm{blal}}$, and the relative error defined as:

$E_{t}=\frac{\Theta_{t, \mathrm{fm}}-\Theta_{t, \mathrm{blm}}}{\Theta_{t, \mathrm{blm}}}$

These data were already presented elsewhere (Ref. [20]). In order to validate the film model for other $\operatorname{Pr}$ numbers, Merkin [7] obtained values of $\Theta^{\prime}(0)$ for $n=0$ and both for $P r=1$ and $P r=7$. In Table 3 the results of $P r=1$ are listed and in Table 4 those pertaining to $P r=7$. In Fig. 2 the results are presented graphically. A glance at Table 3 shows that $-\Theta^{\prime}(0)^{*}$ amounts to 0.5672 for $P r=1$, which is in good agreement with $\Theta^{\prime}(0)^{*}$ of Table 1, provided by Ostrach [19]. This very small difference is an indication of the numerical accuracy. The tabulated values of $E_{t}$ indicate that for suction, i.e. $f_{w}>0$ and $\phi_{t}>0$, the film model predictions correspond well to the numerical results, even for very large suction rates. For large injection rates, on the other hand, the deviation increases dramatically. However, the film model deviates less than $6 \%$ from the boundary layer model for $-0.864 \leq \phi_{t} \leq 4.320$. For this lowest value of $\phi_{t}$ injection already causes a $50 \%$ reduction in heat transfer. For this highest value of $\phi_{t}$, suction enhances heat transfer by more than a factor of four. 
Table 4. Numerical results of Merkin [7] and film model prediction of heat transfer $(n=0, \operatorname{Pr}=7)$

\begin{tabular}{llllll}
\hline $\begin{array}{l}\text { Merkin [7] } \\
f_{w}\end{array}$ & $-\Theta^{\prime}(0)$ & $\begin{array}{l}\text { Eq. (23) } \\
\Theta_{t, \text { blm }}\end{array}$ & $\begin{array}{l}\text { Eq. (26) } \\
\phi_{t}\end{array}$ & $\begin{array}{l}\text { Eq. } \\
\Theta_{t, \mathrm{fm}}\end{array}$ & \multicolumn{1}{c}{$\begin{array}{l}\text { Eq. } \\
E_{t}\end{array}$} \\
\hline-0.3 & 0.0072 & 0.0068 & -5.976 & 0.015 & $120.6 \%$ \\
-0.2 & 0.0614 & 0.058 & -3.984 & 0.076 & $31.0 \%$ \\
-0.1 & 0.3172 & 0.301 & -1.992 & 0.315 & $4.7 \%$ \\
0.0 & 1.0543 & 1.000 & 0.000 & 1.000 & $0.0 \%$ \\
0.1 & 2.4416 & 2.316 & 1.992 & 2.301 & $-0.6 \%$ \\
0.2 & 4.2996 & 4.078 & 3.984 & 4.060 & $-0.4 \%$ \\
0.3 & 6.3347 & 6.008 & 5.976 & 5.991 & $-0.3 \%$ \\
\hline
\end{tabular}

\subsection{Exerted friction}

Eichhorn [6] and Merkin [7] obtained values of the dimensionless friction $f^{\prime \prime}(0)$ for various $f_{w}$. The ratio of actually exerted friction and friction without mass transfer follows as:

$\frac{\mathrm{f}^{\prime \prime}(0)}{f^{\prime \prime}(0)^{*}}=\Theta_{u, \mathrm{blm}}$.

In order to validate the film model correction factor $\Theta_{u, f m}$, provided by Eq. (22), it is applied to free convective flow and compared with Eq. (28). Accordingly, the dimensionless mass flux $\phi_{u}$ is determined with the help of Eqs. (16) and (26) as:

$\phi_{u}=-\frac{f_{w}(n+3)}{\Theta^{\prime}(0)^{*}}$.

To free convective flow along an impermeable vertical plate applies:

$\tau^{*}=4 \varrho\left(\frac{v}{x}\right)^{2} f^{\prime \prime}(0)^{*}\left(\frac{G r_{x}}{4}\right)^{3 / 4}$,

see Ostrach [19] or Eichhorn [6] among others. In Table 1 values of $f^{\prime \prime}(0)^{*}$ for various Prandtl numbers are listed, taken from Ostrach [19].

Combining Eqs. (21), (25) and (30) yields:

$-f^{\prime \prime}(0)^{*} \Theta^{\prime}(0)^{*}=\frac{1}{3}$.

Table 1 illustrates that strictly speaking this equation is correct only for $\operatorname{Pr} \approx 1$, so that the validity of the presented film model is limited to values of $P r$ which are about unity.

For $n=0$ and $\operatorname{Pr}=0.73$ values of $f^{\prime \prime}(0)$ were computed by Eichhorn [6] as a function of $f_{w}$. In Table 5 these results are tabulated. This table also includes $\phi_{u}$, the pertaining film model correction factor $\Theta_{u, f \mathrm{~m}}, \Theta_{u, \text { blm }}$, and the relative error defined as:

$E_{u}=\frac{\Theta_{u, \mathrm{fm}}-\Theta_{u, \mathrm{blm}}}{\Theta_{u, \mathrm{blm}}}$

Tables 6 and 7 contain the results for $P r=1$ and $P r=7$ $(n=0)$, obtained by Merkin [7]. In Fig. 3 the results of the film model and boundary layer model are presented graphically.
Table 5. Numerical results of Eichhorn [6] and film model prediction of exerted friction $\left(n=0, P_{r}=0.73\right)$

\begin{tabular}{ccllll}
\hline \multicolumn{2}{l}{ Eichhorn [6] } & Eq. (28) & Eq. (29) & Eq. (22) & \multicolumn{2}{l}{ Eq. (32) } \\
$f_{w}$ & $f^{\prime \prime}(0)$ & $\Theta_{u, \mathrm{blm}}$ & $\phi_{u}$ & $\Theta_{u, \mathrm{fm}}$ & $E_{u}$ \\
\hline-1.0 & 0.336 & 0.499 & -5.917 & 0.487 & $-2.4 \%$ \\
-0.8 & 0.399 & 0.592 & -4.734 & 0.579 & $-2.2 \%$ \\
-0.6 & 0.476 & 0.706 & -3.550 & 0.691 & $-2.1 \%$ \\
-0.4 & 0.557 & 0.826 & -2.367 & 0.815 & $-1.3 \%$ \\
-0.2 & 0.627 & 0.930 & -1.183 & 0.929 & $-0.1 \%$ \\
-0.1 & 0.654 & 0.970 & -0.592 & 0.972 & $-0.2 \%$ \\
0.0 & 0.674 & 1.000 & 0.000 & 1.000 & $0.0 \%$ \\
0.1 & 0.684 & 1.015 & 0.592 & 1.011 & $-0.4 \%$ \\
0.2 & 0.681 & 1.010 & 1.183 & 1.005 & $-0.5 \%$ \\
0.3 & 0.668 & 0.991 & 1.775 & 0.982 & $-0.9 \%$ \\
0.4 & 0.644 & 0.955 & 2.367 & 0.946 & $-0.9 \%$ \\
0.5 & 0.611 & 0.907 & 2.959 & 0.901 & $-0.7 \%$ \\
0.6 & 0.573 & 0.850 & 3.550 & 0.849 & $-0.1 \%$ \\
0.7 & 0.530 & 0.786 & 4.142 & 0.796 & $1.3 \%$ \\
0.8 & 0.488 & 0.724 & 4.734 & 0.742 & $2.5 \%$ \\
0.9 & 0.446 & 0.662 & 5.325 & 0.691 & $4.4 \%$ \\
1.0 & 0.409 & 0.607 & 5.917 & 0.642 & $5.8 \%$ \\
\hline
\end{tabular}

Table 6. Numerical results of Merkin [7] and film model prediction of exerted friction $(n=0, \operatorname{Pr}=1)$

\begin{tabular}{llllll}
\hline \multicolumn{2}{l}{ Merkin $[7]$} & Eq. (28) & Eq. (29) & Eq. $(22)$ & Eq. (32) \\
$f_{w}$ & $f^{\prime \prime}(0)$ & $\Theta_{u, \mathrm{blm}}$ & $\phi_{u}$ & $\Theta_{u, \mathrm{~mm}}$ & $E_{\text {w }}$ \\
\hline-1.1 & 0.2998 & 0.4668 & -5.8181 & 0.5008 & $7.2 \%$ \\
-1.0 & 0.3275 & 0.5100 & -5.2891 & 0.5424 & $6.4 \%$ \\
-0.9 & 0.3591 & 0.5592 & -4.7602 & 0.5888 & $5.3 \%$ \\
-0.8 & 0.3946 & 0.6144 & -4.2313 & 0.6401 & $4.2 \%$ \\
-0.7 & 0.4333 & 0.6747 & -3.7024 & 0.6957 & $3.1 \%$ \\
-0.6 & 0.4740 & 0.7381 & -3.1735 & 0.7544 & $2.2 \%$ \\
-0.5 & 0.5148 & 0.8072 & -2.6446 & 0.8140 & $0.8 \%$ \\
-0.4 & 0.5536 & 0.8620 & -2.1157 & 0.8715 & $1.1 \%$ \\
-0.3 & 0.5879 & 0.9154 & -1.5867 & 0.9230 & $0.8 \%$ \\
-0.2 & 0.6154 & 0.9583 & -1.0578 & 0.9641 & $0.6 \%$ \\
-0.1 & 0.6341 & 0.9874 & -0.5289 & 0.9908 & $0.3 \%$ \\
0.0 & 0.6422 & 1.0000 & 0.0000 & 1.0000 & $0.0 \%$ \\
0.1 & 0.6386 & 0.9944 & 0.5289 & 0.9908 & $-0.4 \%$ \\
0.2 & 0.6229 & 0.9699 & 1.0578 & 0.9641 & $-0.6 \%$ \\
0.3 & 0.5959 & 0.9279 & 1.5867 & 0.9230 & $-0.5 \%$ \\
0.4 & 0.5596 & 0.8714 & 2.1157 & 0.8715 & $0.01 \%$ \\
0.5 & 0.5172 & 0.8054 & 2.6446 & 0.8140 & $1.1 \%$ \\
0.6 & 0.4726 & 0.7359 & 3.1735 & 0.7544 & $2.5 \%$ \\
0.7 & 0.4292 & 0.6683 & 3.7024 & 0.6957 & $4.1 \%$ \\
0.8 & 0.3894 & 0.6064 & 4.2313 & 0.6401 & $5.6 \%$ \\
0.9 & 0.3540 & 0.5512 & 4.7602 & 0.5888 & $6.8 \%$ \\
1.0 & 0.3232 & 0.5033 & 5.2891 & 0.5424 & $7.8 \%$ \\
1.1 & 0.2965 & 0.4617 & 5.8181 & 0.5008 & $8.5 \%$ \\
\hline & & & & & \\
\hline
\end{tabular}

Tables 5 and 6 and Fig. 3 illustrate the close agreement between both models for $\operatorname{Pr} \approx 1$. Even for very large negative and positive values of $\phi_{u}$ (i.e. strong blowing and suction) the boundary layer model results approximate the film model lines very well. Tables 5 and 6 reveal that the film model deviates less than $8.5 \%$ from the boundary layer model for $\left|\phi_{u}\right| \leq 5.8181$ and $\operatorname{Pr}=0.73$ and $\operatorname{Pr}=1$. For $\operatorname{Pr}=7$, on the other hand, a great discrepancy between both models is 
Table 7. Numerical results of Merkin [7] and film model prediction of exerted friction $(n=0, P r=7)$

\begin{tabular}{|c|c|c|c|c|c|}
\hline \multicolumn{2}{|c|}{ Merkin [7] } & \multirow{2}{*}{$\begin{array}{l}\text { Eq. (28) } \\
\Theta_{u, \text { bim }}\end{array}$} & \multirow{2}{*}{$\begin{array}{l}\text { Eq. (29) } \\
\phi_{u}\end{array}$} & \multirow{2}{*}{$\begin{array}{l}\mathrm{Eq} .(22) \\
\Theta_{\mathrm{w}, \mathrm{fm}}\end{array}$} & \multirow{2}{*}{$\begin{array}{l}\mathrm{Eq} \cdot(32) \\
E_{u}\end{array}$} \\
\hline$f_{w}$ & $f^{\prime \prime}(0)$ & & & & \\
\hline-2.0 & 0.1665 & 0.3693 & -5.6910 & 0.5169 & $40.0 \%$ \\
\hline-1.5 & 0.2217 & 0.4918 & -4.2682 & 0.6600 & $34.2 \%$ \\
\hline-1.0 & 0.3284 & 0.7285 & -2.8455 & 0.8677 & $19.1 \%$ \\
\hline-0.5 & 0.5350 & 1.1868 & -1.4227 & 1.1399 & $-4.0 \%$ \\
\hline-0.4 & 0.5767 & 1.2793 & -1.1382 & 1.1924 & $-6.8 \%$ \\
\hline-0.3 & 0.6039 & 1.3393 & -0.8536 & 1.2319 & $-8.0 \%$ \\
\hline-0.2 & 0.6017 & 1.3347 & -0.5691 & 1.2372 & $-7.3 \%$ \\
\hline-0.1 & 0.5522 & 1.2249 & -0.2845 & 1.1697 & $-4.5 \%$ \\
\hline 0.0 & 0.4508 & 1.0000 & 0.0000 & 1.0000 & $0.0 \%$ \\
\hline 0.1 & 0.3239 & 0.7185 & 0.2845 & 0.7730 & $7.6 \%$ \\
\hline 0.2 & 0.2193 & 0.4865 & 0.5691 & 0.5749 & $18.2 \%$ \\
\hline 0.3 & 0.1554 & 0.3447 & 0.8536 & 0.4371 & $26.8 \%$ \\
\hline 0.4 & 0.1181 & 0.2620 & 1.1382 & 0.3465 & $32.3 \%$ \\
\hline 0.5 & 0.0949 & 0.2105 & 1.4227 & 0.2852 & $35.5 \%$ \\
\hline 1.0 & 0.0474 & 0.1051 & 2.8455 & 0.1491 & $41.9 \%$ \\
\hline 1.5 & 0.0317 & 0.0703 & 4.2682 & 0.1002 & $42.5 \%$ \\
\hline 2.0 & 0.0238 & 0.0528 & 5.6910 & 0.0753 & $42.6 \%$ \\
\hline
\end{tabular}

observed. In the next section attention is paid to the effect of extremely large blowing and suction on heat transfer and exerted friction.

\section{Asymptotic analysis}

When attention is paid to the film model and boundary layer model results shown in Figs. 2 and 3, the question arises whether there are limiting values of $\Theta_{i, \mathrm{fm}}$ and $\Theta_{u, \mathrm{fm}}$ for large (positive or negative) $\phi_{t}$ and $\phi_{u}$. In this section this supposition is examined in some detail. To this end, $\Theta_{t, \mathrm{fm}}$ and $\Theta_{u, f m}$ are analyzed for large $\left|\phi_{t}\right|$ and $\left|\phi_{u}\right|$, respectively, and compared with the asymptotic results of Refs. $[6,21]$ for large blowing and suction. These asymptotic expressions were derived from the boundary layer equations and are valid and applicable for all values $n$ and $\operatorname{Pr}>0$.

For large positive $\phi_{t}$ Eq. (10) yields:

$\Theta_{t, \mathrm{fm}}=\Xi\left(\phi_{t}\right) \approx \phi_{t} \quad\left(\phi_{t} \rightarrow \infty\right)$,

as $e^{-\phi_{t}}$ tends to zero. This asymptotic expression for large suction has also been found by Eichhorn [6]; from Eq. (17) of this paper $\Theta^{\prime}(0)$ can be derived and combined with Eqs. (23) and (26) to obtain expression (33).

For very large negative $\phi_{t}$ Eq. (10) tends to:

$\Theta_{i, \mathrm{fm}}=\Xi\left(\phi_{t}\right) \approx-\phi_{t} e^{\phi_{t}} \quad\left(\phi_{t} \rightarrow-\infty\right)$.

For this extreme case no asymptotic expression of $\Theta^{\prime}(0)$ has been derived yet from the boundary layer equations.

In the following $\Theta_{u, f m}$ is examined for large suction and blowing. For large positive $\phi_{u}$ it can be verified (with the help of Eq. (33)) that Eq. (22) behaves like:

$\Theta_{u, \mathrm{fm}} \approx \frac{3}{\operatorname{Pr} \phi_{u}} \quad\left(\phi_{u} \rightarrow \infty\right)$.
This relation is in accordance with the asymptotic expansion of Merkin [21] for large suction:

$$
\Theta_{u, \text { asym }} \approx-\frac{1}{\phi_{u} \operatorname{Pr} f^{\prime \prime}(0)^{*} \Theta^{\prime}(0)^{*}}+O\left(\phi_{u}^{-3}\right) \quad\left(\phi_{u} \rightarrow \infty\right),
$$

for $f^{\prime \prime}(0)^{*} \Theta^{\prime}(0)^{*}=-\frac{1}{3}$, thus for $\operatorname{Pr} \approx 1$ only, see Table 1 . For large blowing Eq. (22) behaves like:

$\Theta_{u, \mathrm{fm}} \approx-\frac{3}{\phi_{u}} \quad\left(\phi_{u} \rightarrow-\infty\right)$

The three lines in Fig. 3 indeed tend to the same value of $\Theta_{u, \mathrm{fm}}$ for $\phi_{u} \rightarrow-\infty$, irrespective the value of $P r$. Furthermore, the value of $\Theta_{u, \mathrm{fm}}$ as such amounts to about 0.5 for $\phi_{1 z}=-6$, which is in quantitative agreement with Eq. (37). Relation (37) also agrees with the asymptotic result of Ref. [21]:

$\Theta_{u, \text { asym }} \approx \frac{1}{\phi_{u} f^{\prime \prime}(0)^{*} \Theta^{\prime}(0)^{*}} \quad\left(\phi_{u} \rightarrow-\infty\right)$,

for $f^{\prime \prime}(0)^{*} \Theta^{\prime}(0)^{*}=-\frac{1}{3}$, thus again for $\operatorname{Pr} \approx 1$.

So, by definition, the film model yields a value of unity for the correction factors for zero mass transfer. Furthermore, in this section it has been demonstrated that the film model predictions of heat transfer with large suction coincide with the results of the asymptotic analyses of the boundary layer equations by Refs. $[6,21]$. For large blowing an asymptotic approximation of the heat transfer has not, as yet, been derived from the boundary layer model. The difference between $\Theta_{t, \mathrm{fm}}$ and numerical results, however, increases with increasing negative $\phi_{t}$, see Tables $2-4$. Hence it is concluded that the heat transfer for large negative $\phi_{t}$ will not follow Eq. (34). The film model predictions of exerted friction agree with the asymptotic analysis of the boundary layer equations by Ref. [21] for $\operatorname{Pr} \approx 1$ only, both for large suction and blowing.

In order to fit the film model to the boundary layer model for all $\mathrm{Pr}$, the following modified correction factor is suggested:

$\Theta_{u, \mathrm{fm}}^{+}=\Omega\left(\phi_{u}^{+}, P r\right)$

with $\phi_{u}^{+}$as stretched dimensionless transpiration rate:

$\phi_{u}^{+}=-3 f^{\prime \prime}(0)^{*} \Theta^{\prime}(0)^{*} \phi_{u}=3(n+3) f_{w} f^{\prime \prime}(0)^{*}$,

see Eqs. (22) and (26). For large positive and negative $\phi_{u}^{+}$and all values of $\operatorname{Pr}$ the correction factor $\Theta_{u, \mathrm{fm}}^{+}$matches Eqs. (36) and (38). In Tables $8-10$ the results of Refs. $[6,21]$ are summarized (the same as in Tables 5-7). In these tables $\phi_{u}^{+}$and $\Theta_{u, \mathrm{fm}}^{+}$following Eqs. (22), (39) and (40) are included as well. The results illustrate that, generally speaking, the agreement between modified film model and boundary layer model is augmented for $P r=0.73,1$ and 7. For all these Prandtl numbers the film model now matches the boundary layer results excellently. This feature of the modified film model is 
Table 8. Numerical results of Eichhorn [6] and modified film model prediction of exerted friction $(n=0, \operatorname{Pr}=0.73)$

\begin{tabular}{|c|c|c|c|c|c|}
\hline \multicolumn{2}{|c|}{ Eichhorn [6] } & \multirow{2}{*}{$\begin{array}{l}\text { Eq. (28) } \\
\Theta_{u, b \mathrm{~m}}\end{array}$} & \multirow{2}{*}{$\begin{array}{l}\text { Eq. (40) } \\
\phi_{u}^{+}\end{array}$} & \multirow{2}{*}{$\begin{array}{l}\mathrm{Eq} .(39) \\
\Theta_{u, \mathrm{fm}}^{+}\end{array}$} & \multirow{2}{*}{$\begin{array}{l}\text { Eq. (32) } \\
E_{u}\end{array}$} \\
\hline$f_{w}$ & $f^{\prime \prime}(0)$ & & & & \\
\hline-1.0 & 0.336 & 0.499 & -6.066 & 0.477 & $-4.4 \%$ \\
\hline-0.8 & 0.399 & 0.592 & -4.853 & 0.569 & $-3.8 \%$ \\
\hline-0.6 & 0.476 & 0.706 & -3.640 & 0.682 & $-3.4 \%$ \\
\hline-0.4 & 0.557 & 0.826 & -2.426 & 0.809 & $-2.1 \%$ \\
\hline-0.2 & 0.627 & 0.930 & -1.213 & 0.926 & $-0.4 \%$ \\
\hline-0.1 & 0.654 & 0.970 & -0.607 & 0.971 & $-0.1 \%$ \\
\hline 0.0 & 0.674 & 1.000 & 0.000 & 1.000 & $0.0 \%$ \\
\hline 0.1 & 0.684 & 1.015 & 0.607 & 1.011 & $-0.4 \%$ \\
\hline 0.2 & 0.681 & 1.010 & 1.213 & 1.004 & $-0.6 \%$ \\
\hline 0.3 & 0.668 & 0.991 & 1.820 & 0.980 & $-1.1 \%$ \\
\hline 0.4 & 0.644 & 0.955 & 2.426 & 0.942 & $-1.4 \%$ \\
\hline 0.5 & 0.611 & 0.907 & 3.033 & 0.894 & $-1.4 \%$ \\
\hline 0.6 & 0.573 & 0.850 & 3.640 & 0.841 & $-0.1 \%$ \\
\hline 0.7 & 0.530 & 0.786 & 4.246 & 0.786 & $0.0 \%$ \\
\hline 0.8 & 0.488 & 0.724 & 4.853 & 0.732 & $1.1 \%$ \\
\hline 0.9 & 0.446 & 0.662 & 5.459 & 0.680 & $2.7 \%$ \\
\hline 1.0 & 0.409 & 0.607 & 6.066 & 0.631 & $4.0 \%$ \\
\hline
\end{tabular}

Table 9. Numerical results of Merkin [7] and modified film model prediction of exerted friction $(n=0, P r=1)$

\begin{tabular}{|c|c|c|c|c|c|}
\hline $\begin{array}{l}\text { Merkin } \\
f_{w}\end{array}$ & {$[7]$} & $\begin{array}{l}\text { Eq. (28) } \\
\Theta_{u, \text { bim }}\end{array}$ & $\begin{array}{l}\text { Eq. }(40) \\
\phi_{u}^{+}\end{array}$ & $\begin{array}{l}\mathrm{Eq.} \mathrm{(39)} \\
\Theta_{u, \mathrm{fm}}^{+}\end{array}$ & $\begin{array}{l}\text { Eq. (32) } \\
E_{u}\end{array}$ \\
\hline-1.1 & 0.2998 & 0.4668 & -6.3578 & 0.4631 & $-0.8 \%$ \\
\hline-1.0 & 0.3275 & 0.5100 & -5.7798 & 0.5036 & $-1.3 \%$ \\
\hline-0.9 & 0.3591 & 0.5592 & -5.2018 & 0.5497 & $-1.7 \%$ \\
\hline-0.8 & 0.3946 & 0.6144 & -4.6238 & 0.6016 & $-2.1 \%$ \\
\hline-0.7 & 0.4333 & 0.6747 & -4.0459 & 0.6592 & $-2.3 \%$ \\
\hline-0.6 & 0.4740 & 0.7381 & -3.4679 & 0.7214 & $-2.3 \%$ \\
\hline-0.5 & 0.5148 & 0.8072 & -2.8899 & 0.7864 & $-2.6 \%$ \\
\hline-0.4 & 0.5536 & 0.8620 & -2.3119 & 0.8507 & $-1.3 \%$ \\
\hline-0.3 & 0.5879 & 0.9154 & -1.7339 & 0.9096 & $-0.8 \%$ \\
\hline-0.2 & 0.6154 & 0.9583 & -1.1560 & 0.9575 & $-0.8 \%$ \\
\hline-0.1 & 0.6341 & 0.9874 & -0.5780 & 0.9890 & $1.6 \%$ \\
\hline 0.0 & 0.6422 & 1.0000 & 0.0000 & 1.0000 & $0.0 \%$ \\
\hline 0.1 & 0.6386 & 0.9944 & 0.5780 & 0.9890 & $-0.5 \%$ \\
\hline 0.2 & 0.6229 & 0.9699 & 1.1560 & 0.9575 & $-1.3 \%$ \\
\hline 0.3 & 0.5959 & 0.9279 & 1.7339 & 0.9096 & $-1.8 \%$ \\
\hline 0.4 & 0.5596 & 0.8714 & 2,3119 & 0.8507 & $-2.1 \%$ \\
\hline 0.5 & 0.5172 & 0.8054 & 2.8899 & 0.7864 & $-2.4 \%$ \\
\hline 0.6 & 0.4726 & 0.7359 & 3.4679 & 0.7214 & $-2.0 \%$ \\
\hline 0.7 & 0.4292 & 0.6683 & 4.0459 & 0.6592 & $-1.4 \%$ \\
\hline 0.8 & 0.3894 & 0.6064 & 4.6238 & 0.6016 & $-0.8 \%$ \\
\hline 0.9 & 0.3540 & 0.5512 & 5.2018 & 0.5497 & $-0.3 \%$ \\
\hline 1.0 & 0.3232 & 0.5033 & 5.7798 & 0.5036 & $0.1 \%$ \\
\hline 1.1 & 0.2965 & 0.4617 & 6.3578 & 0.4631 & $0.3 \%$ \\
\hline
\end{tabular}

also confirmed by Fig. 4 where $\Theta_{u, f \mathrm{~m}}^{+}$is depicted against $\phi_{u}^{+}$ and the results of Refs. $[6,21]$ included. Summarizing, from the film model and asymptotic analysis of Ref. [21] a modified film model correction factor $\Theta_{u, f m}^{+}$is constructed which is recommended for future computations of free convective friction in the presence of wall transpiration.

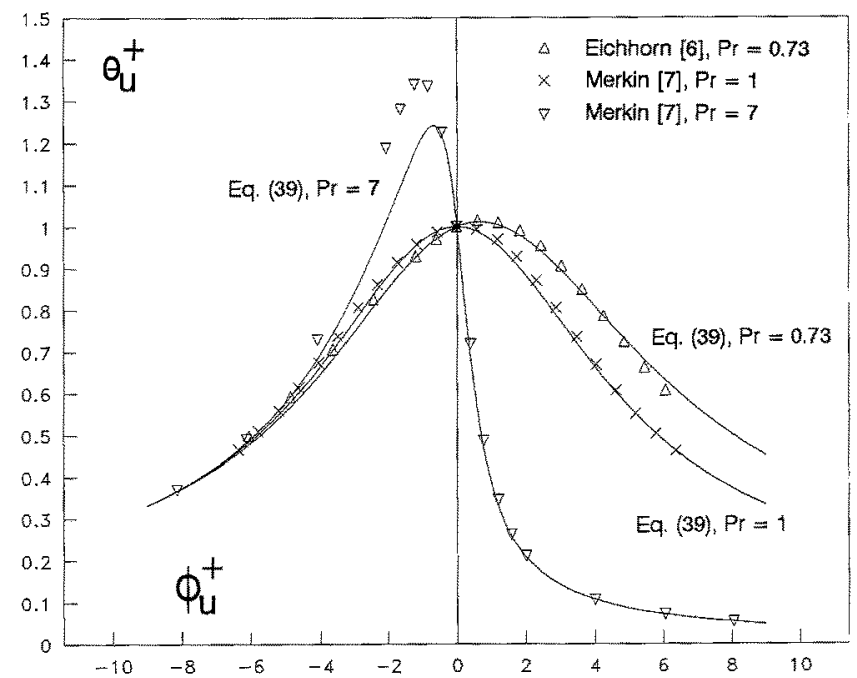

Fig. 4. The effect of transpiration on exerted friction, according to Eichhorn [6], Merkin [7] and the modified film model

Table 10. Numerical results of Merkin [7] and modified film model prediction of exerted friction $(n=0, P r=7)$

\begin{tabular}{|c|c|c|c|c|c|}
\hline \multicolumn{2}{|c|}{ Merkin [7] } & \multirow{2}{*}{$\begin{array}{l}\text { Eq. }(28) \\
\Theta_{u, \mathrm{bim}}\end{array}$} & \multirow{2}{*}{$\begin{array}{l}\text { Eq. }(40) \\
\phi_{u}^{+}\end{array}$} & \multirow{2}{*}{$\begin{array}{l}\text { Eq. (39) } \\
\Theta_{u, \mathrm{fm}}^{+}\end{array}$} & \multirow{2}{*}{$\begin{array}{l}\text { Eq. (32) } \\
E_{u}\end{array}$} \\
\hline$f_{w}$ & $f^{\prime \prime}(0)$ & & & & \\
\hline-2.0 & 0.1665 & 0.3693 & -8.1144 & 0.3688 & $-0.1 \%$ \\
\hline-1.5 & 0.2217 & 0.4918 & -6.0858 & 0.4861 & $-1.2 \%$ \\
\hline-1.0 & 0.3284 & 0.7285 & -4.0572 & 0.6863 & $-5.4 \%$ \\
\hline-0.5 & 0.5350 & 1.1868 & -2.0286 & 1.0192 & $-14.1 \%$ \\
\hline-0.4 & 0.5767 & 1.2793 & -1.6229 & 1.1002 & $-14.0 \%$ \\
\hline-0.3 & 0.6039 & 1.3393 & -1.2172 & 1.1786 & $-12.0 \%$ \\
\hline-0.2 & 0.6017 & 1.3347 & -0.8114 & 1.2355 & $-7.4 \%$ \\
\hline-0.1 & 0.5522 & 1.2249 & -0.4057 & 1.2103 & $-1.2 \%$ \\
\hline 0.0 & 0.4508 & 1.0000 & 0.0000 & 1.0000 & $0.0 \%$ \\
\hline 0.1 & 0.3239 & 0.7185 & 0.4057 & 0.6816 & $-5.1 \%$ \\
\hline 0.2 & 0.2193 & 0.4865 & 0.8114 & 0.4541 & $-6.7 \%$ \\
\hline 0.3 & 0.1554 & 0.3447 & 1.2172 & 0.3271 & $-5.1 \%$ \\
\hline 0.4 & 0.1181 & 0.2620 & 1.6229 & 0.2532 & $-3.4 \%$ \\
\hline 0.5 & 0.0949 & 0.2105 & 2.0286 & 0.2059 & $-2.2 \%$ \\
\hline 1.0 & 0.0474 & 0.1051 & 4.0572 & 0.1053 & $-0.02 \%$ \\
\hline 1.5 & 0.0317 & 0.0703 & 6.0858 & 0.0704 & $-0.1 \%$ \\
\hline 2.0 & 0.0238 & 0.0528 & 8.1144 & 0.0528 & $0.0 \%$ \\
\hline
\end{tabular}

\section{Mean heat transfer and friction}

In the above attention has been focused on the effect of mass transfer on local heat transfer and exerted friction. In the following the effect on overall (and mean) heat transfer and friction is analyzed in some detail.

The mean heat transfer follows from:

$\bar{q}=\frac{1}{L} \int_{x=0}^{L} q \mathrm{~d} x$

with:

$q=\Theta_{i, \mathrm{fm}} q^{*}=-\Theta_{t, \mathrm{fm}} \frac{k}{x} \Theta^{\prime}(0)^{*}\left(t_{b}-t_{i}\right)\left(\frac{G r_{x}}{4}\right)^{1 / 4}$, 
see Eqs. (10) and (24). The mean exerted friction is defined as:

$\bar{\tau}=\frac{1}{L} \int_{x=0}^{L} \tau \mathrm{d} x$

with:

$\tau=\Theta_{u, \mathrm{fm}}^{+} \tau^{*}=\Theta_{u, \mathrm{fm}}^{+} 4 \varrho\left(\frac{v}{x}\right)^{2} f^{\prime \prime}(0)^{*}\left(\frac{G r_{x}}{4}\right)^{3 / 4}$,

see Eqs. (22), (30) and (39). For free convection with mass transfer, i.e. $\Theta_{t, \mathrm{fm}} \neq 1$ and $\Theta_{u, \mathrm{fm}}^{+} \neq 1$, the integrals in Eqs. (41) and (43) can, in general, not be solved in closed form, since both $\phi_{t}$ and $\phi_{u}^{+}$depend on $x$. The similarity solution of the equations, however, permits an analytic treatment of the integrals. In this case $\phi_{t}$ and $\phi_{i s}^{+}$, and consequently $\Theta_{t, \mathrm{fm}}$ and $\Theta_{u, \mathrm{fm}}^{+}$, are constant, see Eqs. (10), (22), (26) and (29). Equations (41) and (42) then yield:

$\bar{q}=-\Theta_{t, \mathrm{fr}} \frac{4 k}{3 L} \Theta^{\prime}(0)^{*}\left(t_{b}-t_{i}\right)\left(\frac{G r_{L}}{4}\right)^{1 / 4}$,

and Eqs. (43) and (44):

$\bar{\tau}=\Theta_{u, \mathrm{fm}}^{+} \frac{16}{5} \varrho\left(\frac{v}{L}\right)^{2} f^{\prime \prime}(0)^{*}\left(\frac{G r_{L}}{4}\right)^{3 / 4}$.

Hence, in the special case of constant $\phi_{t}$ and $\phi_{u}^{+}$the mean heat transfer and friction simply follow from multiplying the mean zero mass transfer levels (which are usually documented in the literature) by the - constant - film model correction factors.

\section{Conclusions}

In this note film model correction factors have been derived for the effect. of mass transfer on free convective heat transfer and wall friction along a vertical plate. First, on the basis of the energy equation for a stagnant film the temperature distribution and thermal correction factor $\Theta_{t, \mathrm{fm}}$ have been derived. Subsequently, the momentum equation for the film was derived in which, unlike the conventional film model, the buoyancy terms have been retained. Invoking the Oberbeck-Boussinesq approximations and substitution of the temperature profile resulted in the velocity profile, the exerted friction and an analytical expression for frictional correction factor $\Theta_{u, f m}$.

This novel film model correction factor reveals the major effect of the Prandtl number on friction. Furthermore, it predicts that free convective friction is reduced by both large suction and injection. Next, this frictional correction factor and the thermal correction factor are compared with theoretical results of Refs. [6, 21] for a broad range of transpiration levels. These studies concerned a boundary layer model of free convection along an isothermal vertical plate whereby the governing equations were solved numerically, the Prandtl number ranging from 0.73 to 7 .
The thermal correction factor agreed with the literature within $6 \%$ for $-0.864 \leq \phi_{t} \leq 4.320$ for $P r=0.73,1$ and 7 . For this range of $\phi_{t}$ the basic film model is well suited to describe the effect of mass transfer on free convective heat transfer. The frictional correction factor appeared to agree within $8.5 \%$ with the boundary layer model for $\left|\phi_{u}\right| \leq 5.8181$ and $P r=0.73$ and 1 . For $P r=7$ deviations of more than $10 \%$ were found.

The behaviour of both $\Theta_{t, \mathrm{fm}}$ and $\Theta_{u, f \mathrm{~m}}$ for large $\left|\phi_{t}\right|$ and $\left|\phi_{u}\right|$, respectively, have been examined in detail. Comparing the limiting values of $\Theta_{t, \mathrm{fm}}$ with the asymptotic results of Refs. $[6,21]$ revealed that the they coincide for large positive $\phi_{t}$ only. A comparison between $\Theta_{u, f m}$ and the asymptotic results of Ref. [21] showed that they are practically identical for $P r \approx 1$ and large $\left|\phi_{u}\right|$. On the basis of this insight a modified correction factor $\Theta_{u, \mathrm{fm}}^{+}$has been introduced which correlates well with the boundary layer model for large $\left|\phi_{u}^{+}\right|$ and irrespective the value of $\mathrm{Pr}$.

In the film model considered the induced velocity stems from imposed wall injection or suction. Similar corrections will follow, however, when this velocity originates from a condensing or evaporating vapours. In a previous film analysis of a binary mixture, consisting of a vapour and stagnant noncondensables (see Refs. [3, 4]), we have seen namely hat the diffusional velocity is also constant across the film, likewise suction/injection.

The only condition for this generalization to be true is that the densities of the diffusing and stagnant components are identical. If this is not the case buoyancy driven flow in the film is, besides the temperature gradient, also introduced by the variation in composition of the film. Hence, transport phenomena are then independently affected by the induced velocity and buoyancy, both originating from a concentration gradient across the film.

\section{Acknowledgements}

The author wishes to express his gratitude to Professor J. H. Merkin of the University of Leeds for his numerical solutions of the boundary layer equations. He also wishes to thank Professor H. van Tongeren for his encouragement of this work and the Cornelis Lely Foundation for their financial support.

\section{References}

1. Bannwart, A. C.: Etude théoretique et expérimentale de la condensation d'une vapeur en présence d'incondensables. Thèse de Doctorat, Institut National Polytechnique de Grenoble (1988) (in French)

2. Bannwart, A. C.; Bontemps, A.: Condensation of a vapour with incondensables: an improved gas phase film model accounting for the effect of mass transfer on film thicknesses. Int. J. Heat Mass Transfer 33 (1990) 1465-1474

3. Brouwers, H. J. H.; Chesters, A. K.: Film models for transport phenomena with fog formation: the classical film model. Int. J Heat Mass Transfer 35 (1992) 1-11+2067 (erratum) 
4. Brouwers, H. J. H.: Film models for transport phenomena with fog formation, with application to plastic heat exchangers and condensers, Ph.D. Thesis, Eindhoven University of Technology (1990)

5. Mickley, H. S.; Ross, R. C.; Squyers, A. L.; Stewart, W. E.: Heat, mass, and momentum transfer for flow over a flat plate with blowing or suction, NACA Techn. Note 3208, (1954)

6. Eichhorn, R.: The effects of mass transfer on free convection flow. J. Heat Transfer 82 (1960) 260-263

7. Merkin, J. H., Private communications (1992)

8. Ackermann G.: Wärmeübertragung und molekulare Stoffübertragung im gleichen Feld bei großen Temperatur- und Partialdruckdifferenzen, V.D.I.-Forschungsheft 382, (1937) (in German)

9. Boussinesq, J: Théorie analytique de la chaleur, vol. 2. GauthierVillars, Paris (1903) (in French)

10. Oberbeck, A.: Ueber die Wärmeleitung der Flüssigkeiten bei Berücksichtigung der Strömungen infolge von Temperaturdifferenzen. Ann. Phys. Chem. 7 (1879) $271-292$ (in German)

11. Joseph, D. D.: Stability of convection in containers of arbitrary shape. J. Fluid Mech. 47 (1971) 257-282

12. Eckert, E. R. G.: Introduction to the transfer of heat and mass, p. 158. McGraw-Hill, New York (1950)

13. Mabuchi, I.: The effect of blowing or suction on heat transfer by free convection from a vertical flat plate. Bull. J.S.M.E. 6 (1963) $223-230$

14. Jaluria, Y.: Natural convection heat and mass transfer, Pergamon, New York (1980)

15. Sparrow, E. M.; Cess, R. D.: Free convection with blowing or suction. J. Heat Transfer 83 (1961) 387-389
16. Merkin, J. H.: Free convection with blowing and suction. Int. J. Heat Mass Transfer 15 (1972) 989-999

17. Parikh, P. G.; Moffat, R. J.; Kays, W. M.; Bershader, D.: Free convection over a vertical porous plate with transpiration. Int. J. Heat Mass Transfer 17 (1974) 1465-1474

18. Clarke, J. F.: Transpiration and natural convection: the vertical plate problem. J. Fluid Mech. 57 (part 1), (1973) 45-61

19. Ostrach, S.: An analysis of laminar free convection flow and heat transfer about a flat plate parallel to the direction of the generating body force, NACA Techn. Note 2635, (1952) or NACA Rep. 1111, (1953)

20. Brouwers, H. J. H.: The film model applied to free convection over a vertical plate with blowing or suction, Int. J. Heat Mass Transfer 35 (1992) $1841-1844$

21. Merkin, J. H.: A note on the similarity equations arising in free convection boundary layers with blowing and suction, accepted for publications in ZAMP.

Dr. H. J. H. Brouwers

Dept. of Civil Engineering \& Management

University of Twente

P.O. Box 217

7500 AE Enschede

The Netherlands

Received on January 18, 1993 